\title{
Research on the Applications of Theory of Lexical Chunks and Cultural Equivalence Theory on Chinese for Foreigners Education
}

\author{
Xie Fang ${ }^{1}$ \\ ${ }^{1}$ Yunnan Technology and Business University, \\ Kunming,Yunnan, 650000 China
}

\begin{abstract}
In this paper, we conduct research on the applications of theory of lexical chunks and cultural equivalence theory on Chinese for foreigner education. There are a lot of language chunks in block is different from the special language unit words, phrases, sentences, prefabricated resistance, can be stored as a whole and extract which plays important role in language acquisition. Teaching Chinese as a foreign language, the theory of lexical chunks in such aspects as help memorization and build up your language sense showed a huge advantage. To explore the teaching methods of lexical chunks has important significance to improve the effectiveness of Chinese teaching. Our research proposed the novel paradigm for the education which will be meaningful and helpful.
\end{abstract}

Keywords: Lexical Chunks; Cultural Equivalence; Chinese for Foreigners; Education Pattern.

\section{Introduction}

In recent years, China's market economy by leaps and bounds, each big multinational companies started to enter the Chinese market, learning and understanding of Chinese language and culture is deeply rooted in the hearts of the people gradually, set off a upsurge in learning Chinese around the world, from all over the world come to China to study Chinese language and culture students team also gradually. But, in the process of external Chinese language teaching, as a result of the social culture background, are great differences in the teaching idea, many learners cannot fully adapt to the Chinese culture in the process of learning and teaching process, the communication barriers between them and the Chinese gradually emerge. Students what are cross-cultural communication barriers, how to improve students cross-cultural communication ability in teaching Chinese as a foreign language become a focus in the study of this article. Due to culture directly or indirectly affect the cross-cultural communication of information communication, the question of how to handle well in the second language teaching the relationship between language and culture; How to carry on the culture teaching in language teaching, the organic combination of language and culture, to make the students know the foreign culture through cross-cultural communication in order to improve the communicative competence, is one of the foreign language teaching is the focus of the world which also is the world the most focus in Chinese teaching a research topic [1].

In the early stages of teaching Chinese as a foreign language, the domestic teaching are not fully considering the differences of national cultural background, just from domestic beginner education, since pinyin, bytes, etc. Due to cultural differences, many foreign beginners learn very hard. Since then, the scholar national cultural differences into consideration and the cultivation of the Chinese language learning to the learners in domestic communication ability and began to reform the Chinese language teaching. Cultural factors are implied in the language system, through the language forms such as phonetics, vocabulary, grammar, it can reflect the values of a people, is a standard, social 
conventions, psychological state, thinking mode, etc., and closely related to language comprehension and language use [2]. And Chinese as a second language learners, due to the lack of cultural knowledge of Chinese, in reading and language communication, often do not know why the Chinese say so, so what is the meaning of, and causes communication barriers, so cultural factors lead people is an important part of Chinese as a foreign language course teaching content.

Human language itself contains a lot of language chunks, the theory of lexical chunks in recent years by language researchers' attention and discussion, the theory of Chinese teaching is of great significance. In the general process of teaching Chinese as a foreign language, how to produce the accurate authentic language, has always been a problem worthy to be discussed. Chinese as a foreign language learner created according to the grammar and vocabulary statement although reasonable, but it is not in conformity with the Chinese language, the sentence is not our daily use. This is because the Chinese compared with those of other language has its own characteristics. Language is a typical Chinese parataxis, often with the help of participants' subjective comprehension and the context to achieve meaning to the sentence a whole grasp, lack of morphological change performance form, and widely used function words and it's great to learners of Chinese as a foreign language. Especially in the primary stage, the student union more with the method of direct memory, if simply using the traditional grammar teaching and vocabulary teaching, the learning process will encounter a lot of obstacles which will reduce the students' interest in learning Chinese.

To suggest solutions for the mentioned challenges, in this paper, we conduct research on the applications of theory of lexical chunks and cultural equivalence theory on Chinese for foreigner education. With the emergence of mandarin fever, more and more foreigners learn
Chinese, although in the study and master a lot of vocabulary and grammar, but still can't properly when using collocation, overall inconsistent phenomenon. The following sections provide basic solutions and suggestions for how to enhance the performance of the traditional classes.

\section{The Novel Perspective and Methodology}

The Cultural Equivalence Theory. Culture has very important significance for teaching Chinese as a foreign language. Teaching Chinese as a foreign language to develop the communicative competence is, in fact, cross-cultural communicative competence. At the same time of learning a language learning the target language culture, study Chinese at the same time of learning about the Chinese culture, it is an important content of teaching Chinese as a foreign language which also means to help students better learning Chinese. Culture teaching, refers to the interference of communication cultural factors in the second language teaching in the teaching. Because language is a part of culture, is the carrier of culture and the development basis, so the language can reflect the characteristics of national culture and the cultural differences between different ethnic groups. Such cultural factors in language has a statute on language and language communication, communication across the nation, it may be because of the lack of knowledge of cultural background of a certain word, sentence and misunderstanding, directly affect the communication. The so-called "language communication culture", that is implied in the language system reflect a nation's psychological state, values, lifestyles, ways of thinking, moral standard, non-standard, customs and aesthetic appeal of a special kind of cultural factors, such as the cultural factor is mainly embodied in the language vocabulary, grammar and pragmatics system. Language teaching contains the culture teaching, cultural teaching in teaching Chinese as a foreign language is an 
integral part of, expand the language in the language teaching practice field of vision, enhance the role of Chinese use level [3].

The influence of various cultural factors on teaching Chinese as a foreign language could be summarized as the follows. (1) Way of thinking. The Chinese way of thinking have from big to small, from the more general to the specific characteristics. (2) Correctness or not concept. Chinese prefer the doctrine, but not distinct ideas. (3) Mental attitude. The Chinese on the express way more implicative, inside collect, don't like directly express, usually use indirect language, dedicating approaches in language to humility. Such as life writing or Chinese people like to use suggested, or allusion to the ancient theory of today, and many articles in China has very many, very complicated rhetoric, these are the culture symbol of the Chinese language. (4) Value standard. Don't understand Chinese people's values, it is impossible to understand the Chinese language expression, for example, Chinese people pay attention to collective interests, advocate personal interests should be subordinated to the interests of the state and the collective. Chinese people pay attention to family consciousness, strong family values, with the deeply rooted patriarchal ideas which reflecting the level of a kind of value approaches, pecking other consciousness. (5) These factors will be the effect on teaching Chinese as a foreign language, if can't when the teachers in teaching Chinese to transfer these cultural factors explain clear, precise, appropriately and the student is not deeply understand Chinese can only say that "learning, and I don't know why." which is meaningful.

Both emphasize special cultural words and generalized cultural words, put forward of the concept of "cultural word" are based on people, especially on the relationship between the language and culture of the relationship between vocabulary and culture on the basis of deep understanding. Cross-cultural communication, language, national conditions, the birth of the emerging disciplines such as cultural linguistics, second language teaching from a mere language teaching is gradually focuses on cultural factors, cultural background, the academic background for the study of the cultural words in China has provided fertile soil. Put forward the practical value of words and culture concept, from the ontology level is the first time from the angle of culture on lexical semantic system to classify and the vocabulary can be divided into general words and cultural terms.

The Theory of Lexical Chunks. Domestic use of lexical chunks teaching first appeared in English teaching and language teaching researchers will block theory in the teaching of English is called the vocabulary teaching block. Of this teaching method is more English vocabulary fixed rules and patterns of the whole teaching, make learners overall stored in its memory, when use the overall extraction, complete expression. This method achieved better effect in teaching, the researchers is verified by the experimental method of vocabulary teaching block to improve the accuracy, the expression of fluency in English pronunciation which has a good effect. Chinese language block theory application in the teaching is still in its infancy [4]. Chinese researchers have put forward the important meaning of the teaching of lexical chunks, but how to utilize the teaching of lexical chunks in the Chinese teaching discourse is not much.

Language researchers will Chinese language chunks are classified, although classification in academic circles did not come to an agreement, but in general can be divided into five categories. Five types have different characteristics as a kind of teaching method cannot suitable for all categories. At the same time, the current study not to strict definition of lexical chunks, and we choose the teaching content and teaching methods is beneficial to the principle of teaching, to improve the teaching effect. Therefore, teaching need not strictly define whether language chunks of language units, completely 
can according to the needs of teaching, will use the theory of lexical chunks can explain clearly the similar language chunks of language units, teaching in language chunks teaching form. Therefore, in the teaching of lexical chunks, deal with the teaching content flexibility is an essential Chinese teaching method. The applications of the lexical chunks could be summarized as the following three parts. (1) In the teaching of reading and writing. Strengthen the accumulation of lexical chunks and use written language. Pay attention to the written language of the accumulation of lexical chunks in the reading teaching, namely the written language input: in the writing teaching pays attention to the use of written language chunks, the piece of the output of the written language. (2) Framework for language teaching. The teacher wants to improve the sensitivity to the framework of lexical chunks, is good at discover if there are no special handling in the framework of lexical chunks in the textbooks, and adopt flexible and varied teaching methods, so that the students can not only understand the structure of righteousness, and an element of truth to be embedded. (3) Framework for the teaching of lexical chunks, due to its structure is fixed, the semantic is complete. Therefore, the teacher in the teaching should focus on is the use of the framework of lexical chunks of these products to enable the students to correctly use the phrases in the right and correct place.

The Chinese for Foreigners Education. It is facing students in teaching Chinese as a foreign language, culture, the differences of thinking mode is especially obvious in language teaching, and as a cognitive way of human beings, metaphor is ubiquitous in language teaching. Whether it is a voice, vocabulary, sentence level, or grammatical level, metaphors are subject to a variety of different forms of students to learn a certain impact. To learn language, cannot leave the social background and cultural knowledge, the cognitive theory of metaphor study, not only helps to understand the history of the development of the language, also helps us to express ideas and to know the world. Metaphor is mainly by understanding a thing or a concept to know a thing or concept, this cognitive process can also be understood as to the old, already have the experience to learn new knowledge. In the process of teaching Chinese as a foreign language, students always to accumulate the old knowledge itself, to understand and experience the new knowledge. Metaphor is an important development of the meaning of words. Open dictionary, we can see each word below are listed a series of meanings, center is the most basic meanings and this is the original meaning of vocabulary, general is concrete, original human understanding of the original meaning. Other meanings by the general center through metaphorical mapping are derived. The vocabulary of any language relative to the complex of the objective world and the inner world of the rich delicate is limited, so when people call new things, to express abstract concepts tend to borrow other aspects of vocabulary, that is to say, by means of metaphor, through the concept similarity between source domain and target domain, use the words of the source domain concepts corresponding to express the concept of the target domain. To realize the inner link, in teaching Chinese as a foreign language, we can't stay on the surface of word formation, and should exploit the metaphorical meaning of words and the overall grasp the lexical meaning so as to improve the students' ability in vocabulary acquisition.

The Prospect and the Future of the Education. Teaching Chinese as a foreign language to improve the students' cross-cultural communicative competence is very important, and expanded the influence of the Chinese culture in the process and the propagation force. Therefore, it is important to grasp the cultural connotation and cultural interpretation. It should be through in the whole process of Chinese language teaching. According to students' different learning level earnestly to do a good job 
of cultural interpretation is very important. Cultural interpretation is also about Chinese culture and other cultural achievements are widely absorbing process. Make full use of cultural transmission opportunities to show the world our country cultural landscape, will make the teaching Chinese as a foreign language in our country this multidisciplinary artistic multicultural skills of modern education subjects show more brilliant luster. Chinese as a foreign language vocabulary teaching methods there are many, but the most important thing is to change the teaching methods used in the classroom teaching process and the teachers can be all kinds of theory to practice.

\section{Conclusion}

In this paper, we conduct research on the applications of theory of lexical chunks and cultural equivalence theory on Chinese for foreigner education. Cultural word is an important and essential content of Chinese as a foreign language vocabulary teaching. To explore the definition of the concept and the teaching skills in teaching Chinese as a foreign language, not only has theoretical significance, more practical significance. Language and culture rely on each other and influence each other. Language is the important carrier of culture; Culture of language. Should throughout Chinese culture education in teaching Chinese as a foreign language, try to reflect our mainstream culture, modern culture and influence of social culture in the process of teaching Chinese as a foreign language, make foreigners in Chinese at the same time, enhance the level of the cognition of the culture, identity, to enhance our country's cultural soft power which will obtain specific meaning.

\section{References}

[1] Bao, X., Chen, X., \& Wei, Y. (2014). The methodology of the listening training when teaching chinese for the foreigners. Science Education Article Collects.

[2] Wu Lian. (1994). Marriages between shanghainese and foreigners arouse concern in shanghai. Chinese Education \& Society, 27(4), 53-54.

[3] Liu W Q, Jia Z C. A Survey of Foreign Students' Emotional Attitude towards the Courses of Chinese Artistic Talents[J]. Journal of Research on Education for Ethnic Minorities, 2014.

[4] Zhang X, Yang L. Strategies for the Acquisition of Chinese Rhetorical Question: Based on a Comparison of Chinese Language and Spanish Language[J]. Journal of Guangdong University. 